\title{
PERFORMANCE ON SPLIT TEE TYPE W.F. BEAM-TO-R.H.S.COLUMN CONNECTION USING PLUG WELD
}

\author{
T. Murai ${ }^{1}$ and I. Kohzu ${ }^{2, *}$ \\ ${ }^{1}$ Former Graduate Student, Division of Global Architecture, \\ Graduate School of Eng., Osaka Univ., Suita, Japan \\ ${ }^{2}$ Professor, Division of Global Architecture, Graduate School of Eng., Osaka Univ., Suita, Japan \\ *(Corresponding author: E-mail: kohzu@arch.eng.osaka-u.ac.jp)
}

Received: 22 August 2007; Revised: 11 October 2007; Accepted: 15 October 2007

\begin{abstract}
This paper presents an experimental investigation, dealing with mechanical property on a newly developed split tee type WF beam-to-RHS column connection using both plug and fillet welds in steel moment resisting frame. Initially, strength of plug weld subjected to tensile load has been evaluated from the test result of simple T-T joint experiment. Next, experiment of subassemblage being welded split tee bracket to RHS column by means of plug weld and/or fillet weld has been conducted. And it has been shown that the proposed design formulae can predict fairly well the yield and ultimate strengths of the connection, after comparing with the experimental result.
\end{abstract}

Keywords: Steel moment resisting frame; beam-to-column connection; plug weld; fillet weld; bearing strength; loading experiment

\section{INTRODUCTION}

As an effective solution in order to avoid premature and brittle failure at the beam end due to weld defect and/or excessive strain concentration of welded beam-to-column connection in weak beam type steel moment resisting frame, it may be desired to adopt design method to share damage due to seismic inelastic behavior among the components of the connection, instead of applying conventional method to limit plastic zone only to beam end. For this reason, a newly developed beam-column connecting method is proposed here. In the connection, only tee shaped brackets are incorporated between WF beam and RHS column, as shown in Figure 1. The flange of the bracket is connected to the column face by means of plug welding as well as fillet welding at the corners. The bracket web is bolted together with the beam flange in order to transfer the beam bending moment and shear force to the column. The beam web, if necessary, can be connected to the column through a gusset plate, by using high strength bolts, to transfer beam shear, when the shear is dominant among beam stresses. The present work is intended to verify performance of the proposed connection using both plug and fillet welds, as shown in the figure.

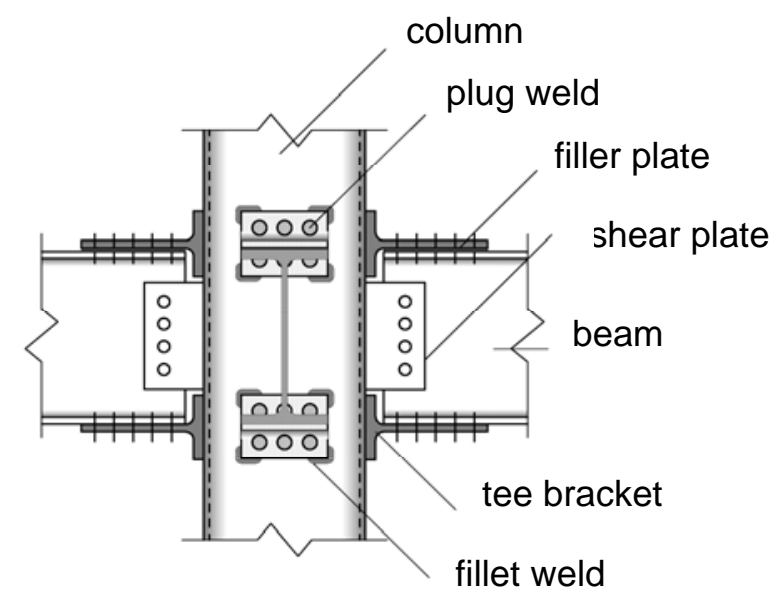

Figure 1. WF Beam-to-RHS Column Connection using Tee Bracket 


\section{TEST ON PLUG WELDED T-T JOINT SUBJECTED TO TENSION}

\subsection{Experimental Procedure}

Plug weld is not commonly used as practical method to join members together in steel building structures, since such welding method is only applicable to shear joints in which the members are subjected to in-plane shear force, in many design standards as A.I.J. 1979[1] and 2005 [2], A.W.S. 2000[3] and A.I.S.C. 2005[4]. However, it seems to be useful to adopt the method to the connections of main members like as columns and beams, because of ease of fabrication and economy in comparison with ordinary beam-to-column connection with through diaphragm in seismic moment resisting frame, if the welding procedure would be adequately performed. For this reason, simple T-stub test was carried out in order to evaluate strength and deformation capacities as well as welding performance of plug welded connection.

Grade SM490B steel plates of JIS G3106 rolled steels specified for welded structure were used for the test. The plates were fabricated and assembled. And then, the flange plates were connected by plug welding, so as to shape T-T joint as illustrated in Figure 2. Mechanical properties of the plates obtained by coupon test are tabulated in Table 1. The lower T-stub was shaped so as to behave as rigid throughout the monotonic tensile experiment, by adding a pair of stiff rib plates between the flange and the web. The upper flange plates of 22 and $32 \mathrm{~mm}$ thick were used and connected to the lower flange plates of $32 \mathrm{~mm}$ thick, by means of plug welding of $28 \mathrm{~mm}$ diameter. $\mathrm{CO}_{2}$ shielded arc welding, using JIS Z3312 YGW11 as MAG welding solid wire for mild and high strength steel up to the tensile strength of $490 \mathrm{~N} / \mathrm{mm}^{2}$, was performed for jointing both the upper and the lower flange plates. Welders belonging to two different fabricators performed plug welding, in order to examine the effect of difference of welding performance on the mechanical properties of the joint. The welding condition by every welder, named as $\mathrm{T}$ or $\mathrm{W}$, is tabulated in Table 2. Specimen types, named as T22 to W32, are identified in Tables 1 and 2.
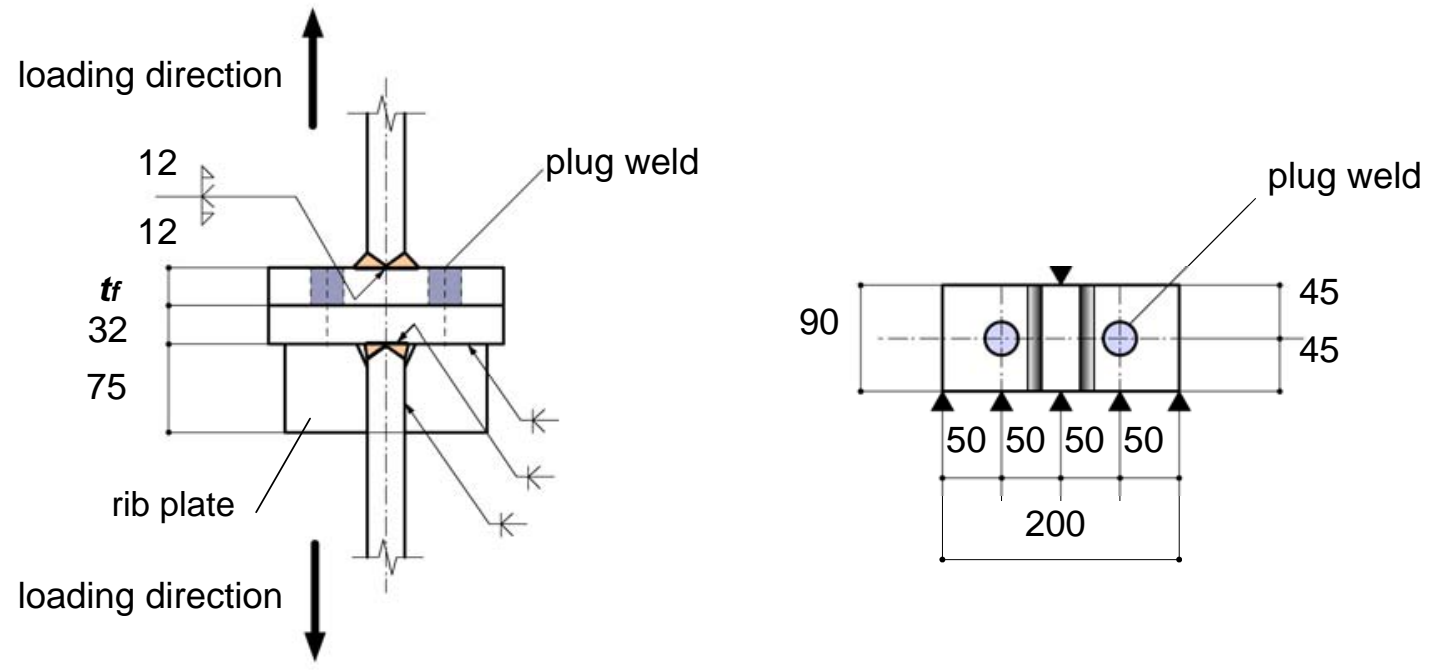

Figure 2. Geometrical Property of T-T Joint Specimen (unit : mm)

Universal testing machine (capacity $2000 \mathrm{kN}$ ) was used so that the specimen was statically loaded under monotonic loading condition by pulling the tip of the web until failure. Clip gauge type extensometers were set on the points shown as triangular symbols in Figure 2, in order to detect local distortion of the specimen during the experiment. The test set-up is shown in Figure 3. 
Table 1. Mechanical Properties of Steel Plates used for T-T Joint

\begin{tabular}{|c|c|c|c|c|c|}
\hline $\begin{array}{c}\text { specimen } \\
\text { type }\end{array}$ & plate thickness & yield strength & tensile strength & yield ratio & elongation \\
\cline { 2 - 6 } & $(\mathrm{mm})$ & $\left(\mathrm{N} / \mathrm{mm}^{2}\right)$ & $\left(\mathrm{N} / \mathrm{mm}^{2}\right)$ & $(\%)$ & $(\%)$ \\
\hline T22 & 22 & 397 & 554 & 72 & 21.2 \\
\hline T32 & 32 & 339 & 523 & 65 & 22.8 \\
\hline W22 & 22 & 390 & 537 & 73 & 22.5 \\
\hline W32 & 32 & 350 & 534 & 65 & 22.7 \\
\hline
\end{tabular}

Table 2. Types of T-T Joint Specimens and Welding Conditions

\begin{tabular}{|c|c|c|c|c|c|}
\hline \multirow{2}{*}{$\begin{array}{l}\text { specimen } \\
\text { type }\end{array}$} & \multirow{2}{*}{ fabricator } & \multirow{2}{*}{$\boldsymbol{t}_{f}(\mathrm{~mm})$} & \multicolumn{3}{|c|}{ plug welding condition } \\
\hline & & & $\begin{array}{l}\text { current } \\
\text { (A) }\end{array}$ & $\begin{array}{c}\text { voltage } \\
(\mathrm{V})\end{array}$ & arc time (sec) \\
\hline $\mathrm{T} 22$ & \multirow{2}{*}{$\mathrm{T}$} & 22 & 280 & 32 & 77 \\
\hline T32 & & 32 & 280 & 32 & 107 \\
\hline W22 & \multirow{2}{*}{ W } & 22 & 240 & 34 & 76 \\
\hline W32 & & 32 & 240 & 34 & 104 \\
\hline
\end{tabular}

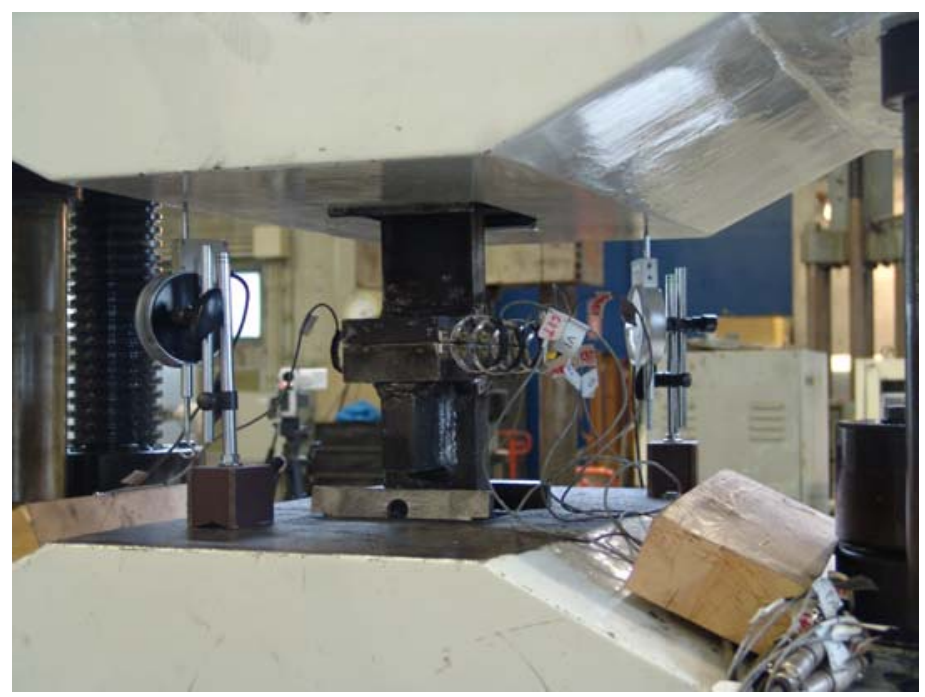

Figure 3. Specimen mounted on the Testing Machine

\section{$2.2 \quad$ Experimental Result}

The typical load-local distortion relations are schematically shown in Figure 4 . In accordance with that the abscissa of the figure gives positive in tension, it is recognized that the edge of flange (tip of flange) is subjected to compressive force. In addition, it can be observed that the load carrying capacity depends on the thickness of upper tee flange.

At the final stage of experiment, the plug welds fractured for every specimen after the upper tee flange deflected due to out of plane bending. Fracture surface in Figure 5, shows that the weld metal is pulled out throughout the cross section of plug weld without any defect like as incomplete penetration. In order to inspect weldability in the above proposed method, macro-structure test was performed, prior to T-T joint test. The example of test result is shown in Figure 6. From the figure, it can be observed that penetration is well achieved both in the upper and the lower flanges. 

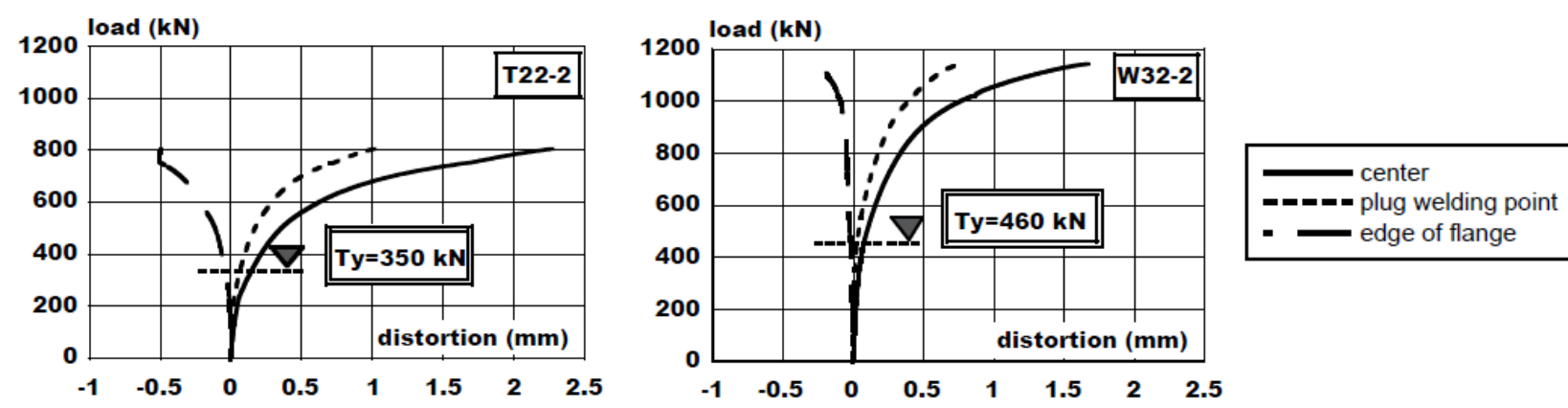

Figure 4. Load-Local Distortion Relation of T-T Joint Specimen

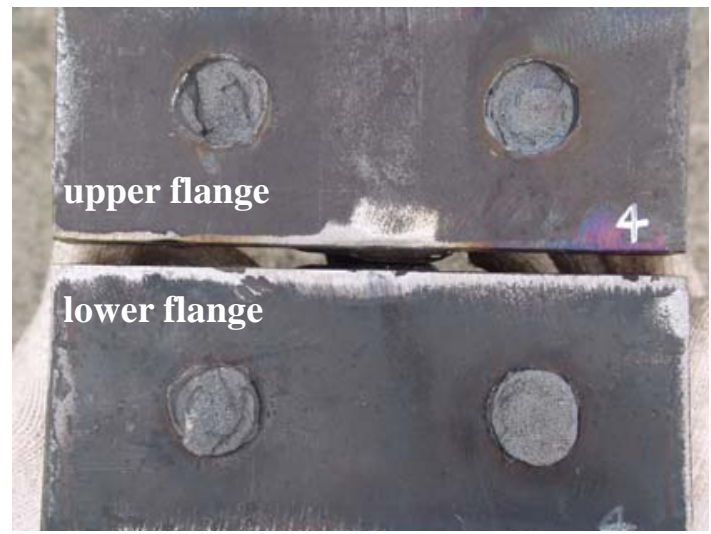

(a) T22-1

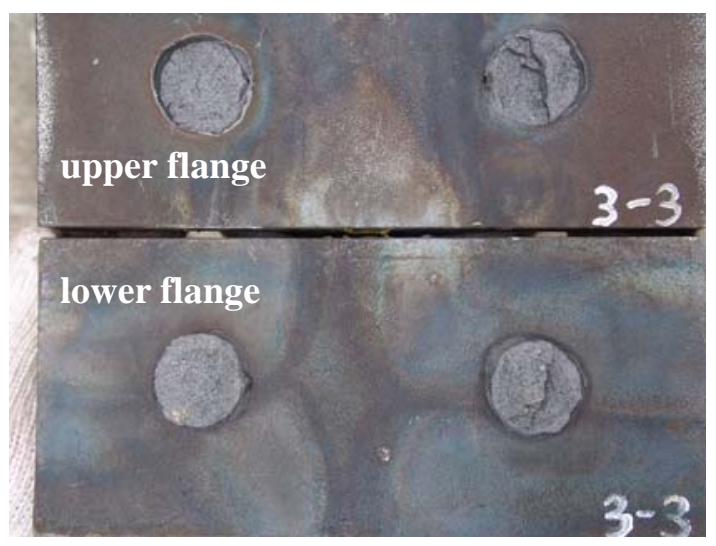

(a) W22-3

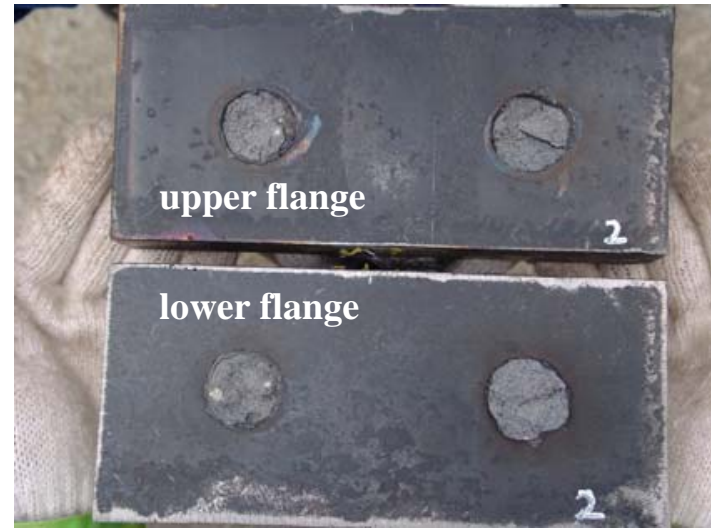

(b) T32-2

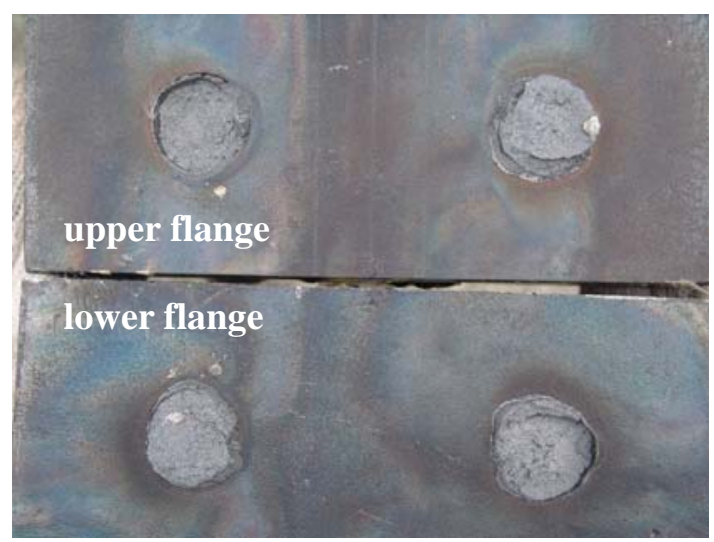

(b) W32-3

Figure 5. Fracture Surface of Plug Weld

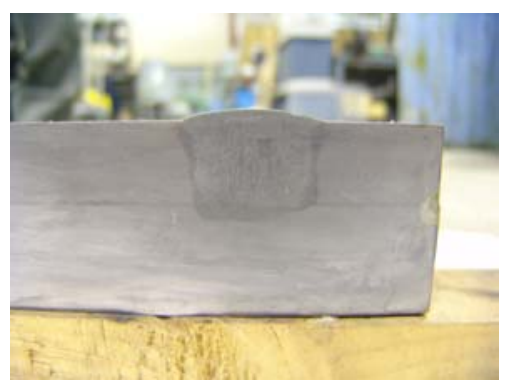

Figure 6. Macro-Structure Test Result of Plug Weld 


\subsection{Discussion}

In this section, the strength of plug weld is evaluated based on the test result. From Figure 4, it can be recognized that force due to prying at the tip of tee flange is generated for every specimen. For this reason, the experimental resisting force of plug weld has to be evaluated in taking into consideration the effect of so called prying action.

Procedure to evaluate the experimental yield strength is as follows.

I. Prepare experimental data set of load $\boldsymbol{T}$ and the corresponding local distortions.

II. Formulate a model in which the upper flange plate is composed of a pair of uniform cantilever beams fixed at the point size / 2 apart from the face of tee web. Where size is the size of fillet weld for reinforcement. Assume the loading condition where each beam is subjected to the loads $\boldsymbol{P}_{\boldsymbol{p}}$ and $\boldsymbol{P}_{\boldsymbol{r}}$ at the plug welded point and the tip of the beam, respectively, and that the reaction $\boldsymbol{T} / \mathbf{2}$ is generated at the fixed point. The above assumption is schematically shown in Figure 7. In the figure, $\delta_{c}, \delta_{p}$ and $\delta_{r}$ are the distortions at the center, the point of plug weld and the edge of the flange, respectively. Derive elastic load-deflection relation of the beam under bending and shear, to formulate $\boldsymbol{P}_{\boldsymbol{p}}$ as a function of $\boldsymbol{T}$ and the local distortion.

III. Estimate load $\boldsymbol{P}_{\boldsymbol{p}}$ by substituting the experimental data of load $\mathbf{T} / \mathbf{2}$ and local distortions in step I for the analytical relation in step II.

IV. Plot the points with co-ordinates, $\left(\boldsymbol{P}_{\boldsymbol{p}}, \boldsymbol{T}\right)$, on a graph.

V. Draw the linear regression line of $\boldsymbol{P}_{\boldsymbol{p}}-\boldsymbol{T}$ plots from the origin to the proportional limit. Draw again a line with a slope of $1 / 3$ of the regression line, and tangent to the $\boldsymbol{P}_{\boldsymbol{p}}-\boldsymbol{T}$ curve.

VI. Define the ordinate of intersection point of the linear regression line and the tangential line, to the experimental yield strength of plug weld, $\boldsymbol{P}_{\boldsymbol{p y}(\boldsymbol{e x})}$. After evaluating $\boldsymbol{P}_{\boldsymbol{p y}(\boldsymbol{e x})}$, it is necessary to confirm that beam yielding occur only after yielding of plug weld. The yield load $\boldsymbol{T}_{\boldsymbol{y}}$ can be found as the abscissa of intersection point.

The procedure from step IV to VI is illustrated in Figure 8. $\quad \boldsymbol{T}_{\boldsymbol{y}}$ in Figure 4, shows the example of experimental yield load obtained from the above procedure.

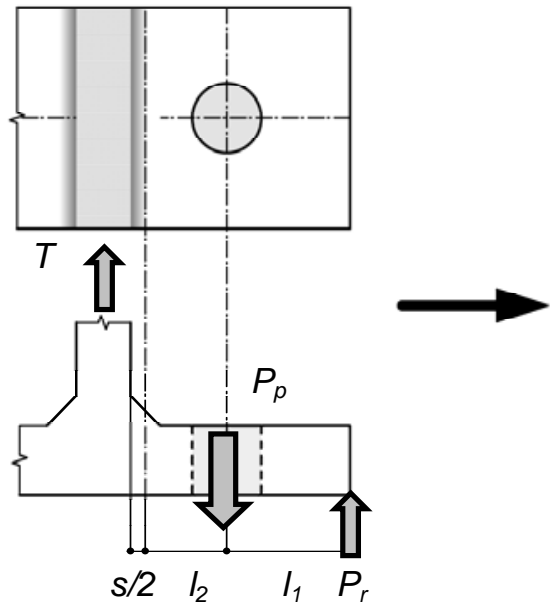

actual tee flange

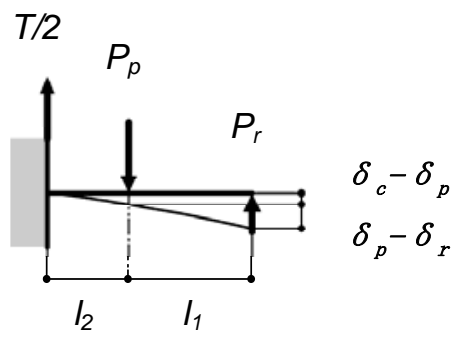

cantilever beam model

Figure 7. Cantilever beam model of actual tee flange subjected to tension 


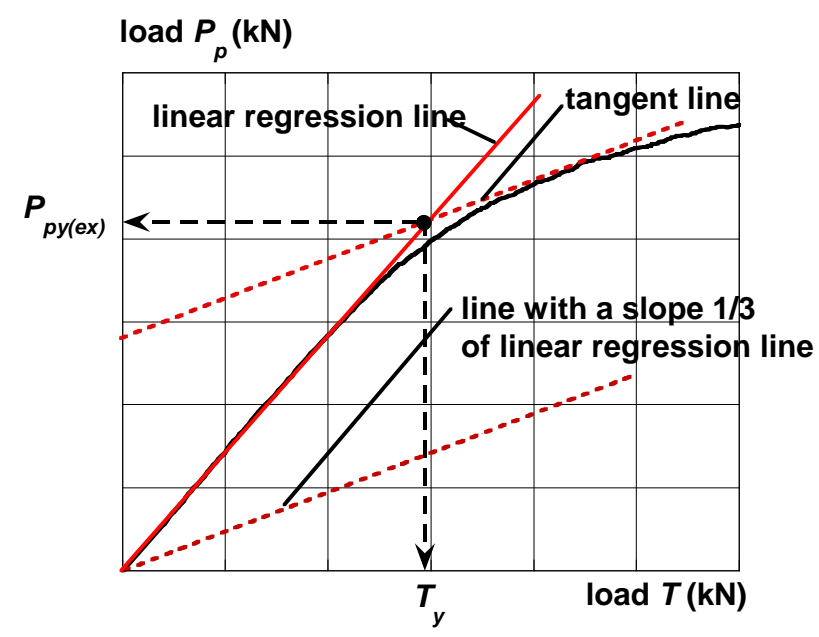

Figure 8. Evaluation of $\boldsymbol{P}_{\boldsymbol{p y}(\boldsymbol{e x})}$ and $\boldsymbol{T}_{\boldsymbol{y}}$ from Experimental Result

The experimental ultimate strength of plug weld can be evaluated by the following procedure.

VII. Perform step-by-step elasto-plastic analysis of the cantilever beam in the manner of numerical integration. Calculate the bending moment corresponding to the rotation angle at the fixed end, under the assumption where a bi-linear moment-curvature relation with the second flexural rigidity of 0.005 times the initial one is applicable to the material of beam.

VIII. Perform bi-linear approximation of the fixed end moment-rotation relation of the beam, in order to derive the moment-rotation relation in the continuous form.

IX. Calculate the rotation angle, $\theta_{\text {end }}$, from the experimental local distortion by using Eq. 1, and evaluate the fixed end moment by substituting the rotation angle for the bi-linear moment-rotation relation.

$\theta_{\text {end }}=\left(\delta_{c}-\delta_{p}\right) / l_{2}$

where $\boldsymbol{I}_{2}$ is the distance between fixed end and the center line of plug weld.

X. Estimate $\boldsymbol{P}_{\boldsymbol{p}}$ so as to satisfy equilibrium condition.

XI. Find the maximum value of $\boldsymbol{P}_{\boldsymbol{p}}$, and define the value as the experimental ultimate strength of plug weld, $\boldsymbol{P}_{p u(e x)}$.

As pointed out in the fracture surface observation in Figure 5, it is rational to consider that plug weld can resist over the cross section until the fracture. Therefore, the estimated strength of plug weld, $\boldsymbol{P}_{\boldsymbol{p s}(\text { cal })}$, can be derived in Eq. 2.

The experimental strength of plug weld, $\boldsymbol{P}_{p s(\boldsymbol{e x})}$, derived from above described procedure, is compared with the estimated value, $\boldsymbol{P}_{p s(c a l)}$.

$P_{p s(c a l)}=\frac{\pi d_{p}^{2}}{4} \sigma_{p s}$

where the letter, $\boldsymbol{s}$, of subscript, $\boldsymbol{p s}$, is rewritten to $\boldsymbol{y}$ in the case of yielding, or $\boldsymbol{u}$ at the ultimate state. Notations, $\boldsymbol{\sigma}_{p s}$ and $\boldsymbol{d}_{\boldsymbol{p}}$, indicate the yield or the ultimate strength of plug weld 
metal, and the diameter of plug weld, respectively. However, in the present case, the material strength of upper flange plate, $\sigma_{f s}$, is used in place of the actual strength of weld metal because of difficulty of direct measurement.

The experimental strength of plug weld, $\boldsymbol{P}_{p s(e x)}$, derived from above described procedure, is compared with the estimated value, $\boldsymbol{P}_{p s(c a l)}$, and the results are shown in Figure 9. From the figure, it can be recognized that $\boldsymbol{P}_{\boldsymbol{p y}(\mathbf{c a l})}$ estimates the yield strength fairly well, though $\boldsymbol{P}_{\boldsymbol{p u ( c a l )}}$ is comparatively lower than $\boldsymbol{P}_{p u(e x)}$ at the ultimate state, in spite of difference between two welding conditions.
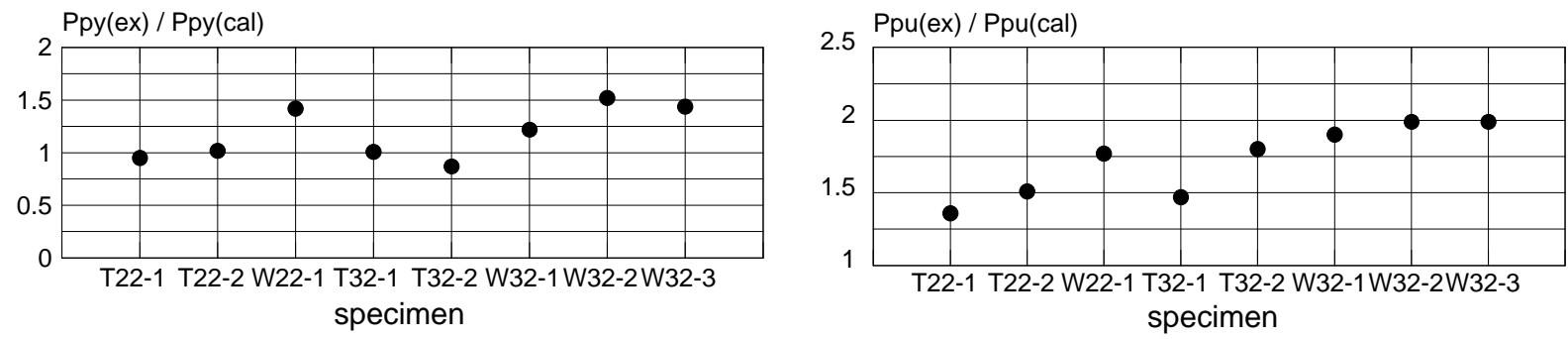

Figure 9. Comparison of Experimental and Estimated Strengths of Plug Weld

\section{TEE BRACKET-RHS COLUMN SUBASSEMBLABE TEST}

\subsection{Objective of Experiment}

In order to confirm the applicability utilizing the proposed connecting method, subassemblage specimens composed of RHS column and split tee bracket were fabricated and used for monotonic tensile loading test.

\subsection{Specimen and Experimental Method}

Figure 10 illustrates the general view of specimen. The columns were cold formed rectangular hollow sections for steel building structure, specified as BCR295, whose yield and tensile strengths in the specification were greater than 295 and $400 \mathrm{~N} / \mathrm{mm}^{2}$, respectively. Tee brackets were made from JIS SS400 wide flange sections. As tabulated in Table 3, the specimens were classified into two groups such as A and C-types, and B and D-types, in accordance with whether the tee flanges were fillet welded to the columns additionally, or not. Their details of welding are shown in Figure 11 and Table 4. When fillet welding, the specimens were tilted to an angle of 45 degrees, so as to shape the bead into right isosceles triangle. Three identical specimens for each type were prepared and tested. Several extensometers were installed in order to measure both global and local deformations of the specimens, as shown in Figures 12 and 13 . Specimens set on a universal testing machine (capacity of $1000 \mathrm{kN}$ ) in Figure 12, were loaded along the direction as shown in Figure 13, until they were torn out or deformed excessively so that interruption of the test was indispensable. 


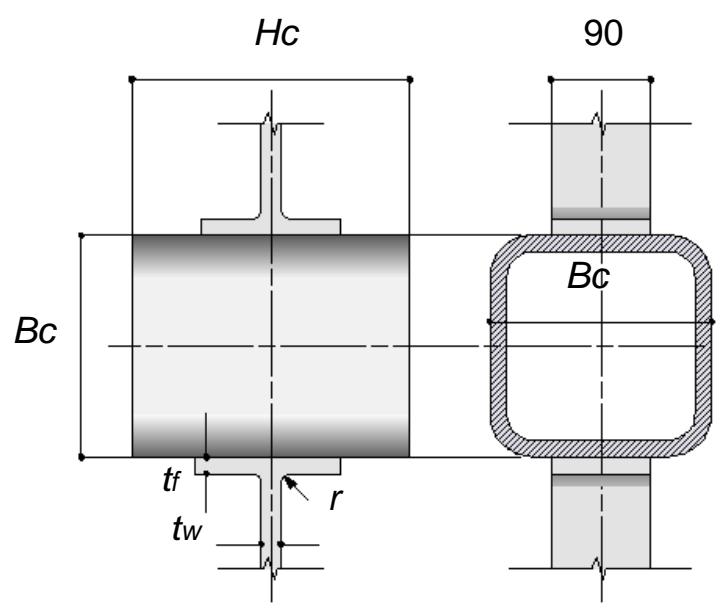

Figure 10. Overall View of Subassemblage Specimen
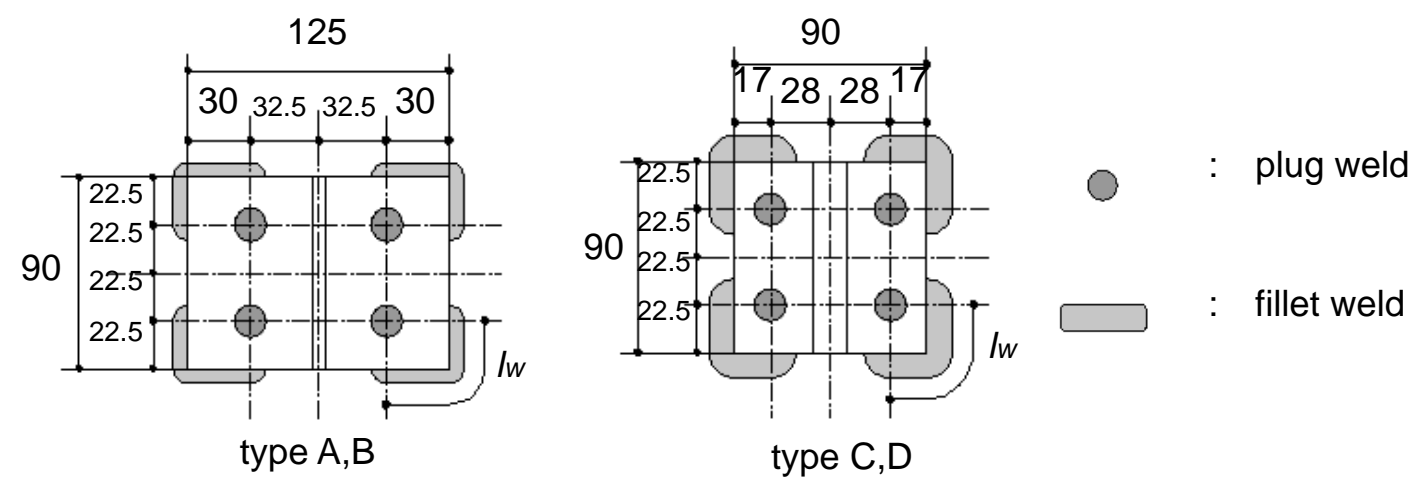

Figure 11. Plug and Fillet Welds of Subassemblage Specimen (unit : mm)

Table 3. Geometrical properties of component members

\begin{tabular}{|c|c|c|c|c|c|c|c|c|}
\hline \multirow{2}{*}{$\begin{array}{l}\text { specimen } \\
\text { type }\end{array}$} & \multicolumn{2}{|c|}{ component member } & $t_{f}$ * & $t_{w}{ }^{*}$ & $r^{*}$ & $B_{c}{ }^{*}$ & $\boldsymbol{H}_{c}{ }^{*}$ & $I_{w}{ }^{*}$ \\
\hline & tee bracket & column & \multicolumn{6}{|c|}{$(\mathrm{mm})$} \\
\hline A & \multirow{2}{*}{$\begin{array}{c}\text { T-220x125x6x9 } \\
\text { (cut from } \\
\text { H-250x125x6x9) }\end{array}$} & \multirow{2}{*}{ SHS-200x200x9 } & \multirow{2}{*}{9} & \multirow{2}{*}{6} & \multirow{2}{*}{8} & \multirow{2}{*}{200} & \multirow{2}{*}{250} & 52.5 \\
\hline B & & & & & & & & - \\
\hline $\mathrm{C}$ & \multirow{2}{*}{$\begin{array}{c}\mathrm{T}-220 \times 90 \times 16 \times 16 \\
\text { (cut from } \\
\text { H-900x300x16x28) }\end{array}$} & \multirow{2}{*}{ SHS-300x300x16 } & \multirow{2}{*}{16} & \multirow{2}{*}{16} & \multirow{2}{*}{18} & \multirow{2}{*}{300} & \multirow{2}{*}{350} & 39.5 \\
\hline $\mathrm{D}$ & & & & & & & & - \\
\hline
\end{tabular}

*: $\quad$ Notations in the table are identified in Figures 10 and 11.

Table 4. Welding Condition

\begin{tabular}{|c|c|c|}
\hline \multirow{2}{*}{ specimen } & \multicolumn{2}{|c|}{ welding condition } \\
\hline & fillet weld & plug weld \\
\hline A & size 7 mm, 1 pass & \multirow{2}{*}{$\begin{array}{c}\text { diameter } 15 \mathrm{~mm} \\
\text { depth : } 9 \mathrm{~mm}\end{array}$} \\
\hline $\mathrm{B}$ & - & \\
\hline $\mathrm{C}$ & size12 mm, 3 passes & \multirow{2}{*}{$\begin{array}{c}\text { diameter } 15 \mathrm{~mm} \\
\text { depth : } 16 \mathrm{~mm}\end{array}$} \\
\hline $\mathrm{D}$ & - & \\
\hline
\end{tabular}




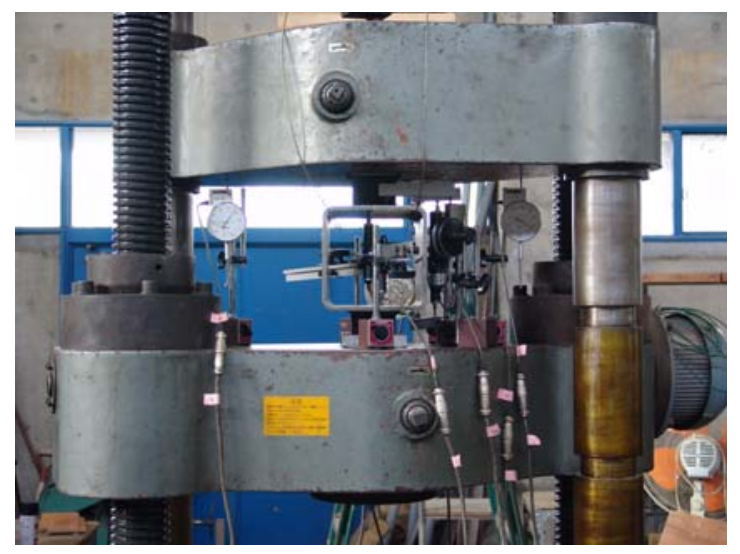

Figure 12. Test Set-Up

loading direction

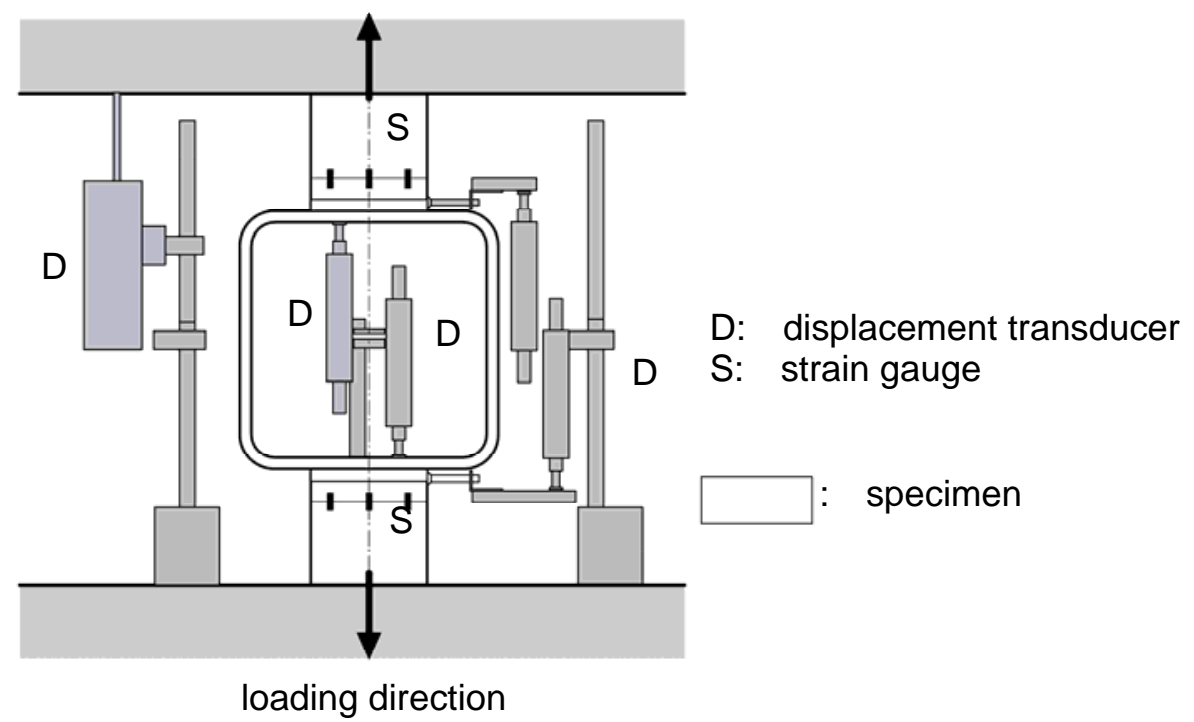

Figure 13. Test Set-Up and Instrumentation of Displacement Transducer and Strain Gauge

\subsection{Mechanical Properties of Materials}

In order to examine the mechanical properties of the component materials, the coupon test was carried out. The obtained results are tabulated in Table 5.

Table 5. Mechanical Properties of Materials

\begin{tabular}{|c|c|c|c|c|c|}
\hline \multirow{2}{*}{$\begin{array}{c}\text { Specimen } \\
\text { type }\end{array}$} & component & yield strength & tensile strength & yield ratio & elongation \\
\cline { 3 - 6 } & $\left(\mathrm{N} / \mathrm{mm}^{2}\right)$ & $\left(\mathrm{N} / \mathrm{mm}^{2}\right)$ & $(\%)$ & $(\%)$ \\
\hline \multirow{3}{*}{ A,B } & tee flange & 303 & 450 & 67 & 23.6 \\
\cline { 2 - 6 } & tee web & 356 & 464 & 77 & 19.3 \\
\cline { 2 - 6 } & column & 347 & 418 & 83 & 23.2 \\
\hline \multirow{3}{*}{ C,D } & tee flange & 287 & 446 & 64 & 23.8 \\
\cline { 2 - 6 } & tee web & 321 & 456 & 70 & 22.3 \\
\cline { 2 - 6 } & column & 417 & 488 & 85 & 20.3 \\
\hline
\end{tabular}




\subsection{Calculated Design Strength of Specimen}

As seen in Figures 10 and 11, the specimen consists of three or four component members like as split tee, column, plug weld and/or fillet weld. For this reason, in order to estimate the strength of the subassemblage specimen as one unit, the strength of each component member initially has to be evaluated. The strength of individual member can be found as the minimum value among the strengths, which have been computed for considerable failure modes, as will be described in following sections. Finally, the overall strength of the subassemblage specimen can be estimated by adopting the lowest of the strengths of the component members.

\subsubsection{Strength of plug weld}

In designing the specimen, three types of failure modes like as mode 1 to 3 , that is, plug weld fracture (mode-1), shear failure of plug weld (mode-2) and punching shear failure of plate (mode-3), were assumed. These three modes are illustrated in Figure 14, and the corresponding design equations to three failure modes are formulated as follows.

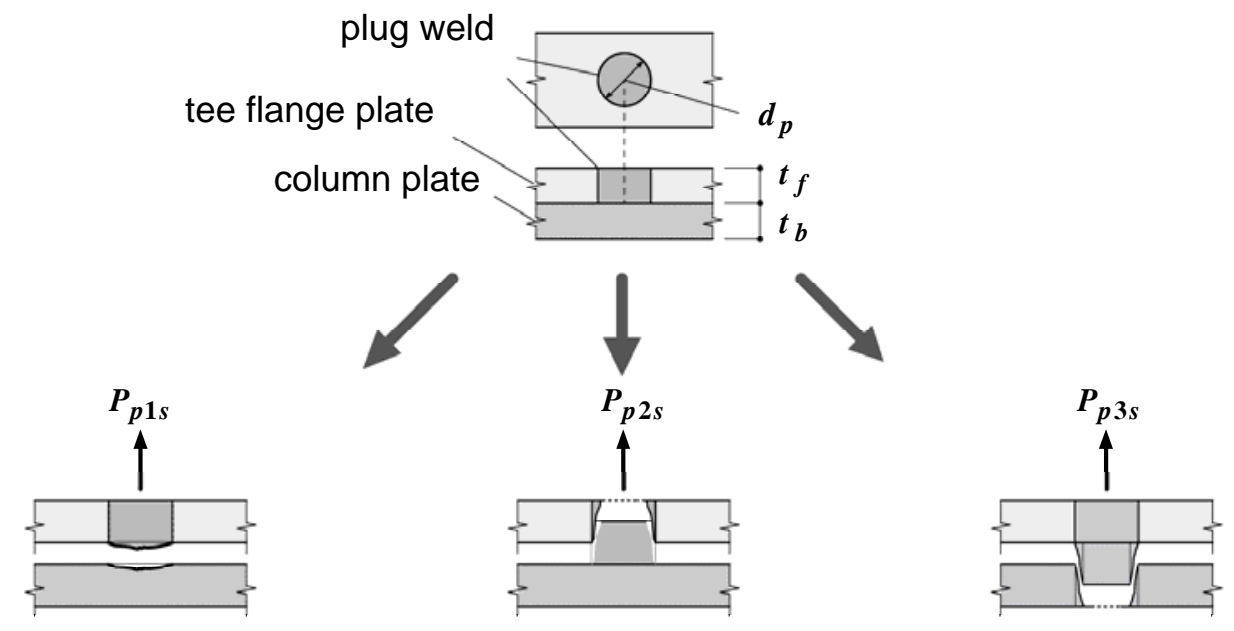

Figure 14. Failure Mechanisms of Plug Weld

For mode 1, Eq. 3, the identical equation with Eq. 2, can be formulated. When the thickness of tee flange plate is comparatively thin, shear yielding or failure of the plate will occur around the plug weld as shown in mode 2, and the strength per single plug weld can be formulated in Eq. 4 . On the other hand, in the case of the connection with the column plate thinner than the tee flange plate, so called punching shear will occur as shown in mode 3, the corresponding strength can be formulated in Eq. 5.

$$
\begin{aligned}
& P_{p 1 s}=\frac{\pi d_{p}^{2}}{4} \sigma_{p s} \\
& P_{p 2 s}=\pi d_{p} t_{f} \frac{\sigma_{f s}}{\sqrt{3}} \\
& P_{p 3 s}=\pi d_{p} t_{b} \frac{\sigma_{c s}}{\sqrt{3}}
\end{aligned}
$$


where $\sigma_{p s}$ and $\sigma_{c s}$ are the yield or tensile strength of plug weld and the column plate, respectively. In Eq. 3, the strength of plug weld refers to the lower of the strengths of tee flange plate and column plate. Finally, the design strength of plug weld in tension can be decided as the minimum among Eqs. 3, 4 and 5, as formulated in Eq. 6.

$$
\boldsymbol{P}_{p s}=\min \left\{\boldsymbol{P}_{p 1 s}, \boldsymbol{P}_{p 2 s}, \boldsymbol{P}_{p 3 s}\right\}
$$

After substituting the material strengths shown in Table 5 for Eqs. 3 to 5, the design strengths of single plug weld for type-A to D specimens can be calculated as in Table 6 .

Table 6. Calculated Strength of Single Plug Weld in Tension

\begin{tabular}{|c|c|c|c|c|c|c|c|c|}
\hline \multirow{2}{*}{$\begin{array}{c}\text { specimen } \\
\text { type }\end{array}$} & \multicolumn{4}{|c|}{ yield strength } & \multicolumn{5}{c|}{ ultimate strength } \\
\cline { 2 - 9 } & $\boldsymbol{P}_{\boldsymbol{p} \mathbf{y}}$ & $\boldsymbol{P}_{\boldsymbol{p} \mathbf{y}}$ & $\boldsymbol{P}_{\boldsymbol{p} \mathbf{y} \boldsymbol{y}}$ & $\boldsymbol{P}_{\boldsymbol{p} \boldsymbol{y}}$ & $\boldsymbol{P}_{\boldsymbol{p} \mathbf{u}}$ & $\boldsymbol{P}_{\boldsymbol{p} \mathbf{u}}$ & $\boldsymbol{P}_{\boldsymbol{p} \mathbf{u}}$ & $\boldsymbol{P}_{\boldsymbol{p u}}$ \\
\cline { 2 - 9 } & \multicolumn{3}{|c|}{$(\mathrm{kN})$} & $(\mathrm{kN})$ & \multicolumn{3}{|c|}{$(\mathrm{kN})$} & \\
\hline A, B & 54 & 69 & 86 & 54 & 80 & 103 & 104 & 80 \\
\hline C, D & 51 & 134 & 180 & 51 & 79 & 208 & 211 & 79 \\
\hline
\end{tabular}

: show the lowest of the strengths which result in $\boldsymbol{P}_{p s}$.

\subsubsection{Strength of tee bracket}

It is well known that three failure modes, like as shown in Figure 15, can be assumed in response of the strength of the component, when bolted T-stub is subjected to tensile force, as has already been reported by Faella et al. [5] and [6]. After substituting the bolt for plug weld, the conventional equations can be applied for strength prediction of the presented connection.
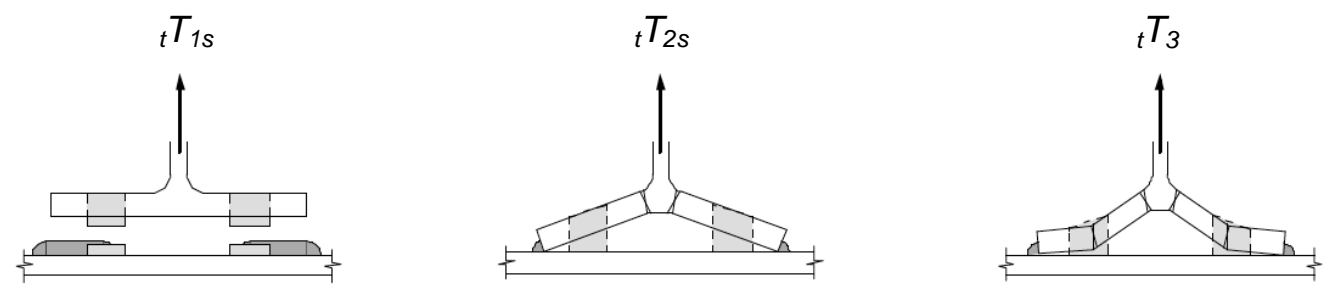

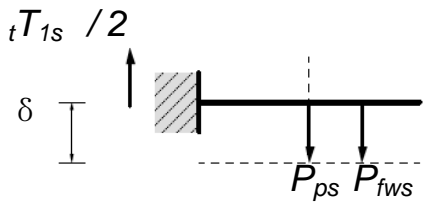

mode 4

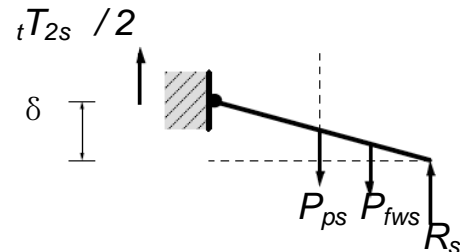

mode 5

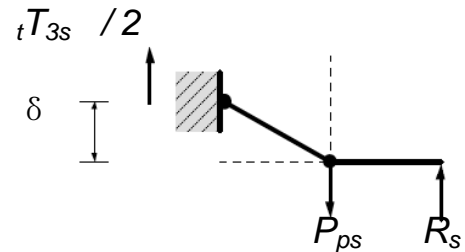

mode 6

Figure 15. Failure Mechanisms of Tee Bracket

When the tee bracket is loaded in tension, it is assumed that the flange behaves like as a pair of cantilever beams as shown in Figure 16. In the figure, $\boldsymbol{r}$ denotes the radius of web fillet. Depending on the stiffness and the strength of tee flange, it can be drawn that there are three failure modes as in Figure 15. 


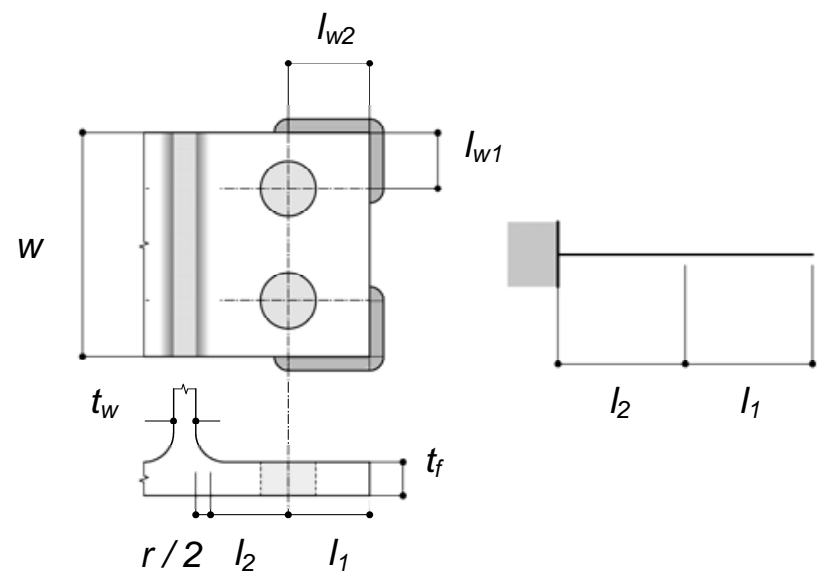

Figure 16. Cantilever Beam Model of Tee Bracket

Mode 4 corresponds to the case where the tee flange is very stiff and yielding or fracture will occur only at the plug weld and/or fillet weld. In this case, the strength of tee bracket, ${ }_{t} \boldsymbol{T}_{\boldsymbol{s} 1}$, can be evaluated in Eq. 7.

${ }_{t} T_{s 1}=2 n P_{p s}+4\left(I_{w 1}+I_{w 2}\right) p_{f w s}$

where $\boldsymbol{n}$ indicates the number of plug weld at each projection of the bracket flange, and $\boldsymbol{P}_{\boldsymbol{p s}}$ is the strength of plug weld determined by Eq. 6 . The second term of the right side in the equation indicates the strength of the fillet weld, and $\boldsymbol{I}_{w 1}, \boldsymbol{I}_{w 2}$ and $\boldsymbol{p}_{\text {fws }}$ are the lengths of fillet weld shown in Figure 16 and the strength of fillet weld per unit length, respectively. $\boldsymbol{p}_{\text {fws }}$ can be calculated using the yield or tensile strength of fillet weld per unit area, $\sigma_{f w s}$, and the throat thickness, $\boldsymbol{a}$, as in Eq. 8. The thickness, $\boldsymbol{a}$, can be evaluated using the size of fillet weld, size , as in Eq. 9.

$$
\boldsymbol{p}_{f w s}=1.4 \boldsymbol{a} \frac{\sigma_{f w s}}{\sqrt{3}}
$$

$a=0.7$ size

In mode 5, failure mechanism can be established when plastic zones are generated at the fixed ends of the bracket flanges and the plug welds as well as the fillet welds. In this case, the strength of tee bracket, ${ }_{\boldsymbol{t}} \boldsymbol{T}_{\mathbf{s} 2}$, can be evaluated as follows.

$\boldsymbol{T}_{\boldsymbol{s} 2}=\frac{2\left(\boldsymbol{w} \boldsymbol{M}_{0 s}+\boldsymbol{n} \boldsymbol{P}_{p s} \boldsymbol{I}_{1}+2 \boldsymbol{M}_{f w s} \boldsymbol{I}_{w 1}+\boldsymbol{p}_{f w s} \boldsymbol{I}_{w 2}^{2}\right)}{\boldsymbol{l}}$

where $\boldsymbol{w}$ and $\boldsymbol{l}_{\mathbf{1}}$ are the width and the partial length of tee bracket as shown in Figure 16, respectively. $\quad \boldsymbol{M}_{\mathbf{0} \text { s }}$ is the fully plastic or ultimate moment per unit width of bracket flange, and can be calculated using the thickness of flange, $\boldsymbol{t}_{\boldsymbol{f}}$, and using the yield or tensile strength of flange as equated in Eq. 11. If the fillet weld at the free end of bracket flange becomes yielding or collapse due to out of plane bending, the fully plastic or ultimate moment of fillet weld per unit 
length, $\boldsymbol{M}_{\text {fws }}$, as equated in Eq. 12, has to be accounted in Eq. 10. The total length of bracket flange as a cantilever beam, $\boldsymbol{l}$, can be equated as in Eq. 13.

$$
\begin{aligned}
& M_{0 s}=\frac{\boldsymbol{t}_{f}{ }^{2} \sigma_{f s}}{4} \\
& M_{f w s}=\frac{\boldsymbol{a}^{2} \sigma_{f w s}}{4} \\
& I=I_{1}+I_{2}
\end{aligned}
$$

If yielding does occur only at the bracket flanges as shown in Figure 15, the strength of tee bracket in mode 6, $\boldsymbol{T}_{\boldsymbol{s} 3}$, can be equated as follows.

$$
{ }_{t} T_{s 3}=\frac{4 w M_{0 s}}{l_{2}}
$$

After applying the above formulae and the material strengths to every type of subassemblage specimen, the design strength of tee bracket, ${ }_{\boldsymbol{t}} \boldsymbol{T}_{\boldsymbol{s}}$, can be estimated from Eq. 15, as the lowest of the strengths of three types of failure modes in Table 7.

$$
{ }_{t} T_{s}=\min \left\{T_{t},{ }_{t} T_{s 2}, T_{t} T_{s 3}\right\}
$$

Table 7. Calculated Strength of Tee Bracket

\begin{tabular}{|c|c|c|c|c|c|c|c|c|c|}
\hline \multirow{2}{*}{ specimen type } & \multicolumn{4}{|c|}{ yield strength (kN) } & \multicolumn{4}{c|}{ ultimate strength (kN) } & \multirow{2}{*}{ failure } \\
\cline { 2 - 11 } & $\boldsymbol{t}_{\boldsymbol{y} \mathbf{1}}$ & $\boldsymbol{t}_{\boldsymbol{y} \mathbf{2}}$ & $\boldsymbol{t}_{\boldsymbol{y} \mathbf{3}}$ & $\boldsymbol{t}_{\boldsymbol{y}}$ & $\boldsymbol{t}_{\boldsymbol{u} \mathbf{1}}$ & ${ }_{\boldsymbol{t}} \boldsymbol{T}_{\boldsymbol{u} \mathbf{2}}$ & ${ }_{\boldsymbol{t}} \boldsymbol{T}_{\boldsymbol{u} \mathbf{3}}$ & ${ }_{\boldsymbol{t}} \boldsymbol{T}_{\boldsymbol{u}}$ & mode \\
\hline A & 466 & 185 & 120 & 120 & 666 & 270 & 179 & 179 & mode 6 \\
\hline B & 214 & 138 & 82 & 82 & 318 & 205 & 122 & 122 & mode 6 \\
\hline C & 511 & 404 & 1260 & 404 & 794 & 627 & 1970 & 627 & mode 5 \\
\hline D & 203 & 314 & 1260 & 203 & 315 & 488 & 1970 & 315 & mode 4 \\
\hline
\end{tabular}

: show the lowest of the strengths which result in ${ }_{t} \boldsymbol{T}_{s}$.

\subsubsection{Strength of column due to out-of-plane bending}

Since the width-thickness ratio of column used in this experiment, is comparatively large, the plate of the column attached to the tee bracket tends to deform out of plane. It is well known that strength of RHS column due to out-of-plane bending can be well predicted by applying yield line theory, as has been reported by Morita et al. [7], Yamamoto et al. [8] and Harada et al. [9]. Taking into consideration existence of fillet weld at the corners of tee flange, two types of failure mechanism can be assumed, as shown in Figure 17. 


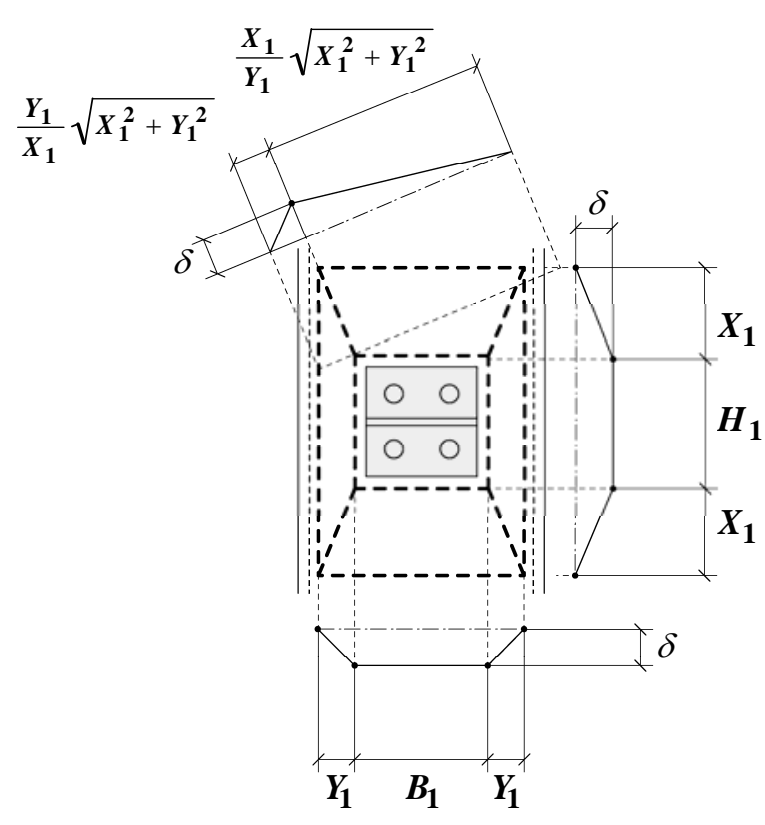

mode 7 (type- A and C)

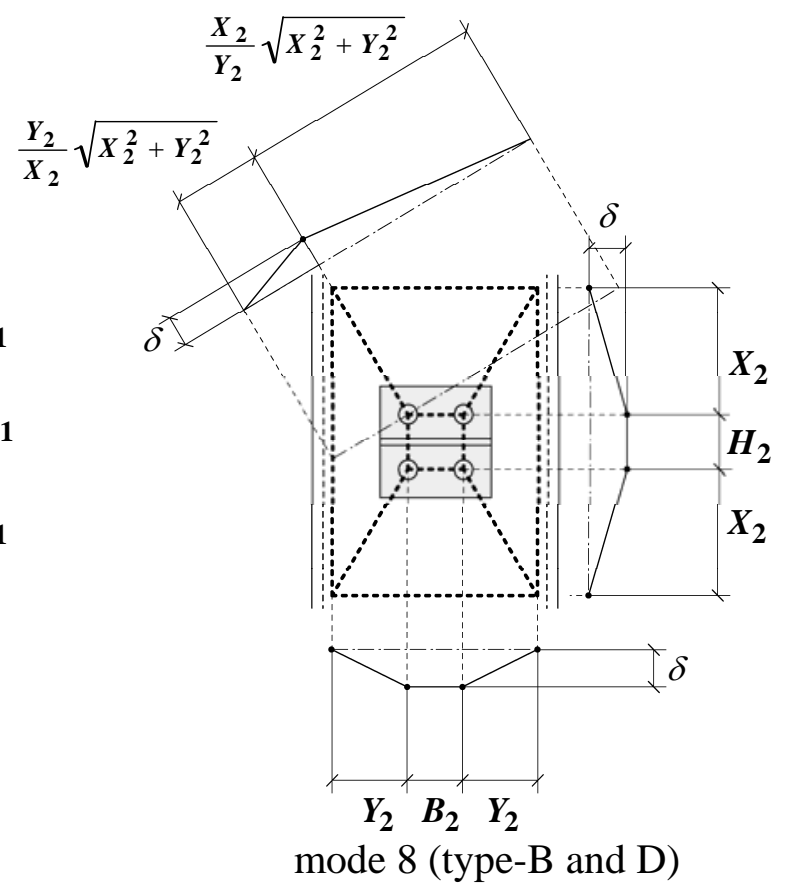

mode 8 (type-B and D)

Figure 17. Failure Mechanisms of RHS Column

As a result, the tensile force transferred to the column through the tee bracket, ${ }_{c} \boldsymbol{T}_{\boldsymbol{s} m}$, can be derived from Eq. 16 . The subscript $\boldsymbol{m}$ is set to 1 or 2, for mode 7 or 8, respectively.

${ }_{c} T_{s m}=\frac{t_{c}^{2} \sigma_{c s}}{2}\left(\frac{2 Y_{m}+B_{m}}{X_{m}}+\frac{4 X_{m}+2 H_{m}}{Y_{m}}\right)$

$\boldsymbol{X}_{\boldsymbol{m}}$ and $\boldsymbol{Y}_{\boldsymbol{m}}$ in Eq. 16 can be calculated by Eqs. 17 and 18.

$X_{m}=\frac{1}{2} \sqrt{Y_{m}\left(B_{m}+2 Y_{m}\right)}$

$Y_{m}=\frac{1}{2}\left(B_{c}-B_{m}-2 r_{c} t_{c}\right)$

where $\boldsymbol{t}_{\boldsymbol{c}}$ and $\boldsymbol{r}_{\boldsymbol{c}}$ denote the thickness and the corner radius of column, respectively. Notations, $\boldsymbol{B}_{\boldsymbol{m}}$ and $\boldsymbol{H}_{\boldsymbol{m}}$, are the lengths shown in Figure 17.

After substituting the specific values for Eq. 16, the column strength due to out-of-plane bending, ${ }_{c} \boldsymbol{T}_{\boldsymbol{s}}$, can be evaluated by applying the corresponding $\boldsymbol{m}$ to Eq. 19. The results are tabulated in Table 8.

$$
{ }_{c} T_{s}={ }_{c} T_{s m}
$$


Table 8. Calculated Out-of-Plane Bending Strength of Column

\begin{tabular}{|c|c|c|c|c|}
\hline \multirow{2}{*}{$\begin{array}{c}\text { specimen } \\
\text { type }\end{array}$} & $\boldsymbol{c}_{\boldsymbol{y}}$ & $\boldsymbol{c}_{\boldsymbol{u}}$ & $\boldsymbol{m}$ & failure mode \\
\cline { 2 - 5 } & $(\mathrm{kN})$ & $(\mathrm{kN})$ & & \\
\hline A & 359 & 433 & 1 & mode 7 \\
\hline B & 171 & 206 & 2 & mode 8 \\
\hline C & 877 & 1026 & 1 & mode 7 \\
\hline D & 514 & 602 & 2 & mode 8 \\
\hline
\end{tabular}

Finally, the calculated strength of connection for every specimen, ${ }_{\text {cal }} \boldsymbol{T}_{\boldsymbol{s}}$, can be evaluated as the lowest strength in Tables 7 and 8, by adopting Eq. 20, and the calculated result is summarized in Table 10.

$$
{ }_{c a l} T_{s}=\min \left\{T_{s},{ }_{c} T_{s}\right\}
$$

\subsection{Experimental Result}

The test was terminated after fracture due to bending of tee flanges for A-type specimens, or after rupture due to tearing of plug welds for D-type specimens, whereas the test of B or C-type specimens was interrupted because of excessive deformation due to out of plane bending of column flanges. Typical load-displacement relations obtained from the test result are illustrated in Figure 18. The figure shows responses of the global as well as the local displacements such as the inside measurement of column, the distance between the upper or the lower tee flange and the column detected by displacement transducers shown in Figure 13. From the Figure 18, it can be observed that the load-inside measurement of column relation is very close to the load-global displacement relation in the cases of B and D-type specimens, whereas for A and C-type specimens, the inside measurement of column is comparatively smaller than the global displacement. Since each tee bracket flange of B and D-type specimens is connected to the column at only 4 points by means of plug weld, the global displacement of the specimen is governed by the deformation of column due to out-of-plane bending and it results in lower rigidity of the connection. On the other hand, the stiffness of the connection becomes comparatively higher for A and C-type specimens with fillet welds added to each tee bracket flange at the corner, because the tee bracket can efficiently resist against out-of-plane bending of column plate. Figure 19 shows the typical example of geometrical configuration of the connection after finishing of the test. As observed in (a) of the figure, tee bracket flange of specimen A3 is torn out near the plug weld and the fillet welds are ruptured, with excessive deformation of the tee flange at the center. On the contrary, specimen B2 in (b), whose component members are identical with those of specimen A3, deflects due to excessive out-of-plane deformation of the column, because of absence of fillet welds at the corners of tee bracket flange. Comparison of test results of specimen C1 in (c) and D3 in (d) suggests that fillet welds at the corners of tee flanges are effective in increase of both strength and rigidity of connection.

C and D-type specimens consist of thicker plates of members but lower contact areas between tee flange plates and column faces in comparison with those of A and B-type specimens. Findings obtained from experimental results of 4 types specimens will lead to essential guidelines required in designing the proposed connection illustrated in Figure 1, like as proportioning tee brackets and columns in respect to rigidity of the connection. However, in the present study, the attention is only focused on evaluating the strength of subassemblage specimens. For this reason, further research concerning with rigidity of the subassemblage with different proportions will be needed. 

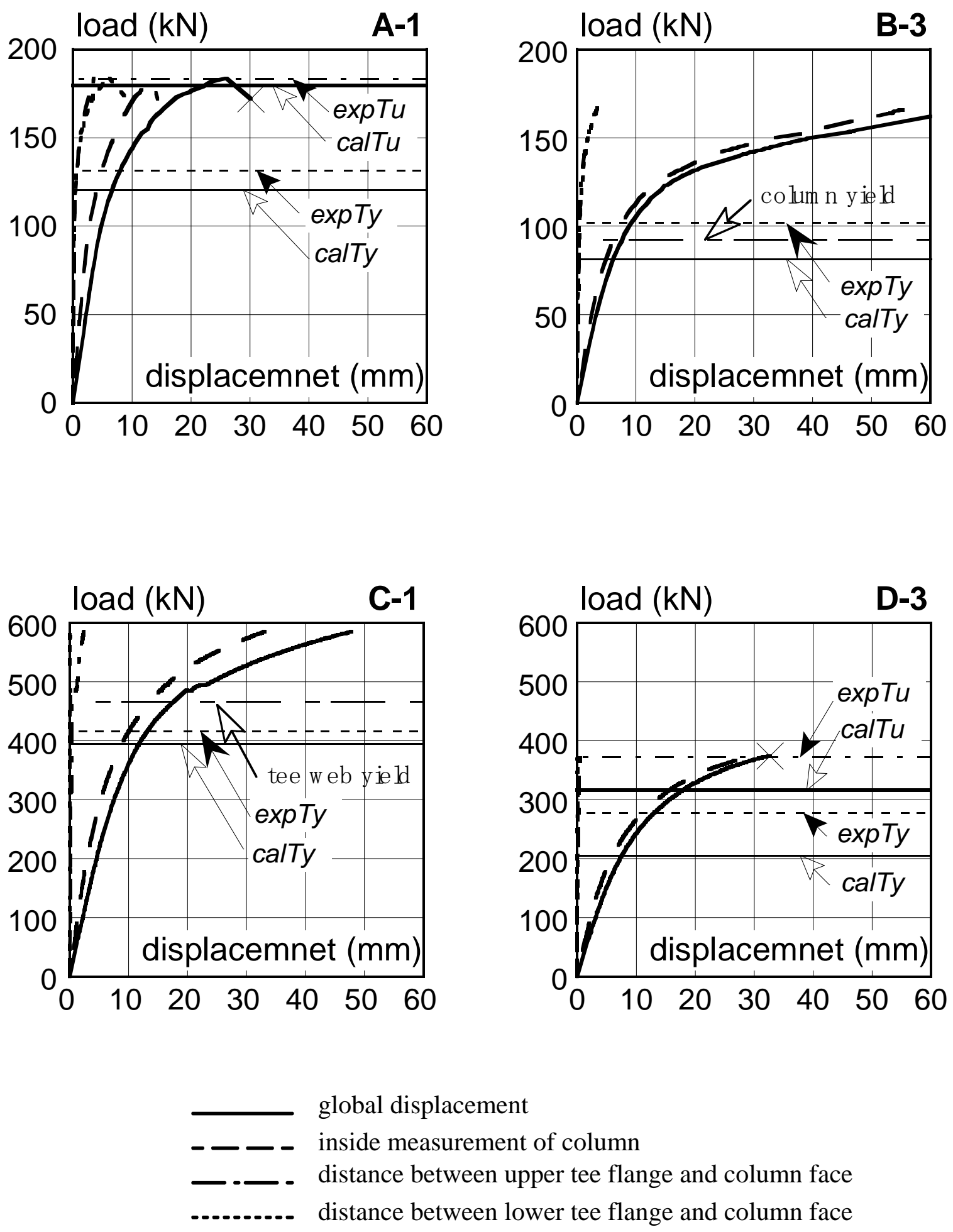

Figure 18. Result of Load-Displacement Relation of Subassemblage Specimen 

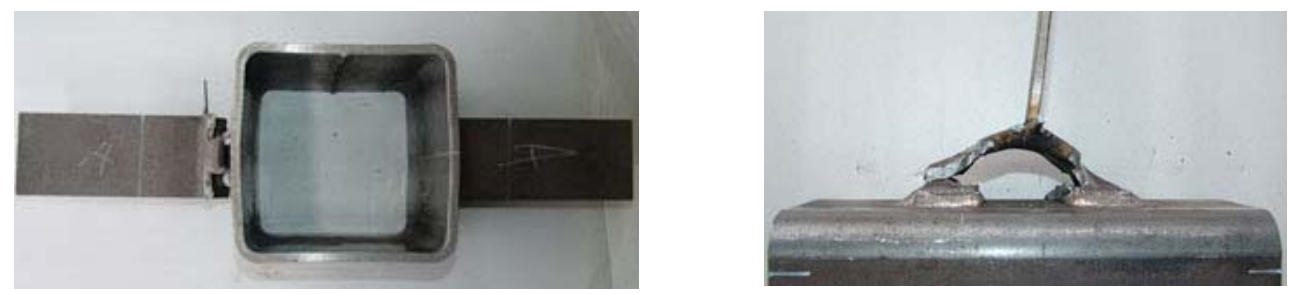

(a) rupture of bracket flange and fillet weld (specimen A3)
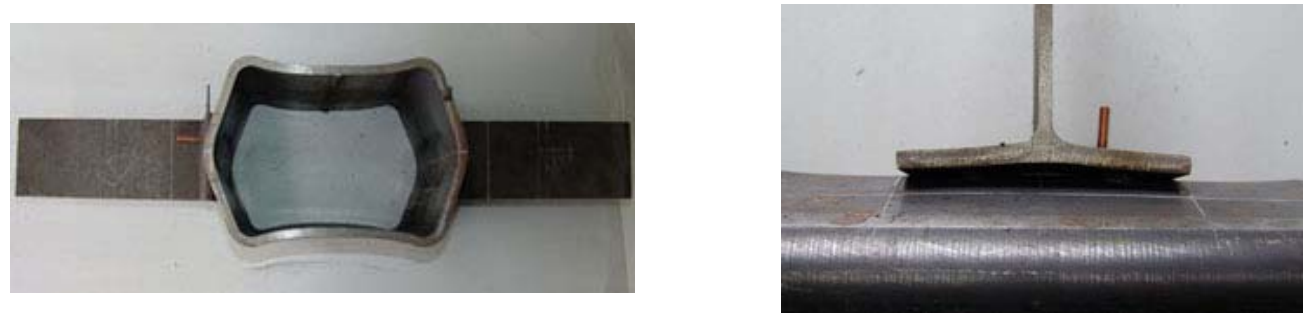

(b) deformed column and flexure of tee bracket flange (specimen B2)
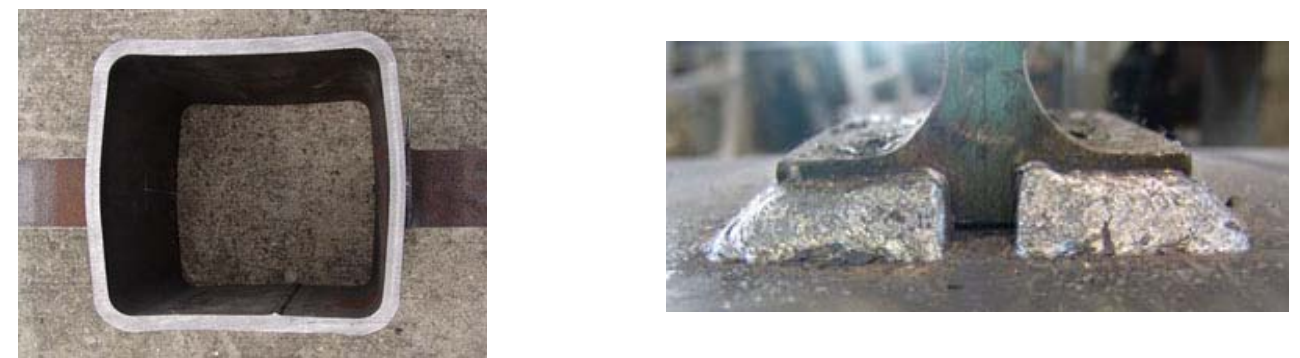

(c) deformed column and detail of fillet weld (specimen C1)
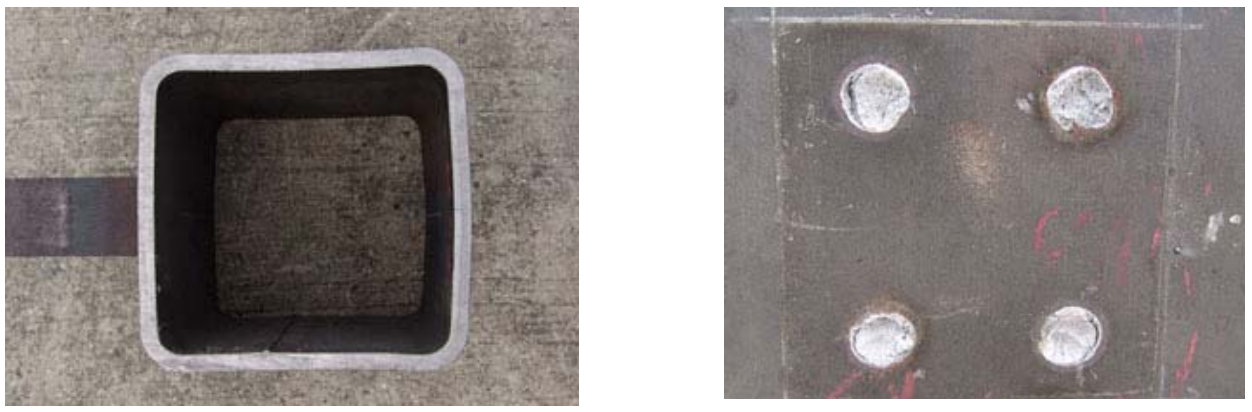

(d) deformed column and fracture surface of plug weld (specimen D3)

Figure 19. Test Result of Subassemblage Specimen 


\subsection{Discussion}

The experimental yield strength for each specimen is defined as follows: In the load-global displacement relation, let draw a straight line having a slope of initial stiffness through the origin, furthermore, draw a tangential line having a slope of one thirds of initial stiffness on the load-global displacement curve and get the intersection point between the above two lines. Set the ordinate of the intersection point as the yield strength. Such procedure is schematically shown in Figure 20.

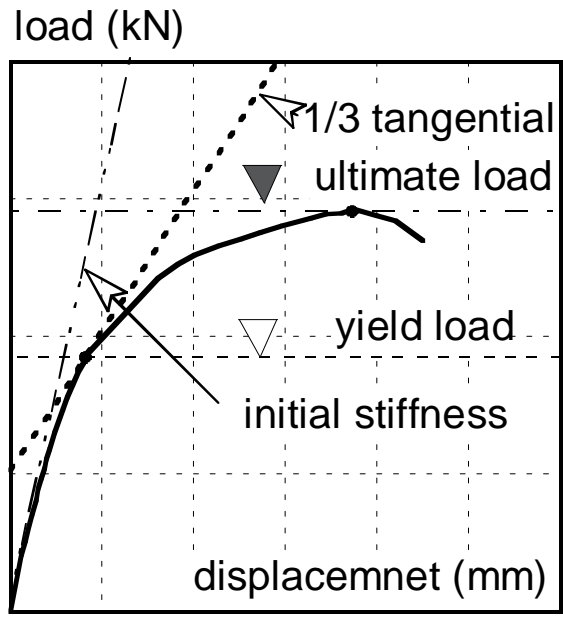

Figure 20. Definition of Experimental Yield Load of Specimen

It is evident from the test result of B -type specimen as shown in (b) of Figure 19 that the failure mode observed after the test termination is somewhat different from the initially predicted mode. That is, the column plate was folded at the center like as house roof along the longitudinal direction. For this reason, other failure modes consisted of three or four yield lines along the longitudinal direction of the column have been considered for four types of specimens, as illustrated in Figure 21. The locations of plastic hinge lines have been identified from the bending moment distribution of the columns which can be idealized as rigid frames. Since the tee bracket flanges are rigidly connected to the columns in the manner of both plug and fillet welds for A and C-type specimens, plastic hinge lines along the longitudinal directions of the columns will be formed just outside the fillet weld lines (mode 9). In the cases of B and D-type specimens, the plastic hinge lines will be formed at the centers of the column faces beneath the tee bracket flanges (mode 10), because the bracket flanges are connected to the columns only at the points of plug welds. For this reason, the number 3 or 4 is added to notation $\boldsymbol{m}$, to identify mode 9 or 10 , respectively. From the above consideration, the strength of the connection for two additional failure modes can be evaluated as tabulated in Table 9 .

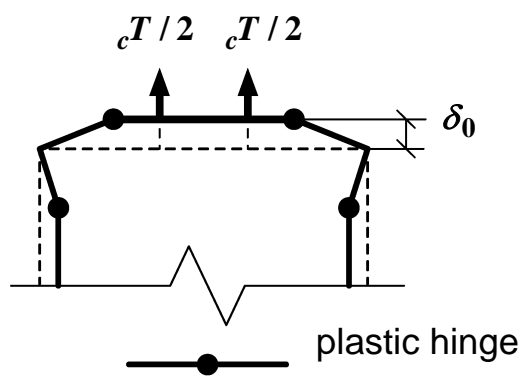

mode 9 (type-A and C)

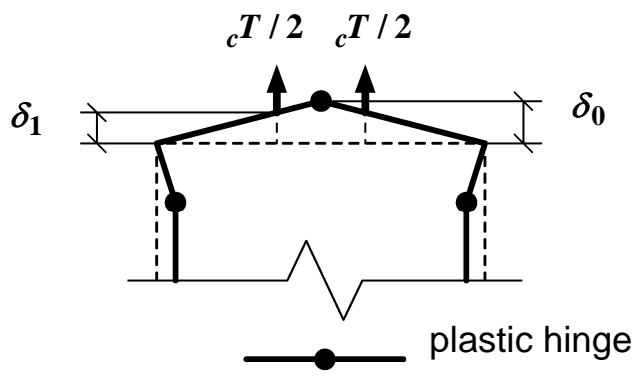

mode 10 (type-B and D)

Figure 21. Additional Failure Mechanisms of Column 
Table 9. Additional Out-of-Plane Bending Strength of Column

\begin{tabular}{|c|c|c|c|c|}
\hline \multirow{2}{*}{$\begin{array}{c}\text { specimen } \\
\text { type }\end{array}$} & yield strength $(\mathrm{kN})$ & ultimate strength $(\mathrm{kN})$ & \multirow{2}{*}{ failure mode } \\
\cline { 2 - 3 } & $\boldsymbol{c}_{\boldsymbol{y}}$ & $\boldsymbol{c}_{\boldsymbol{u}}$ & & \\
\hline A & 150 & 180 & 3 & mode 9 \\
\hline B & 93 & 112 & 4 & mode 10 \\
\hline C & 397 & 464 & 3 & mode 9 \\
\hline D & 290 & 338 & 4 & mode 10 \\
\hline
\end{tabular}

Table 10 summarizes the calculated and the experimental strengths, and the accuracy of prediction. These specific strengths are also shown in Figure 18, as ${ }_{\exp } \boldsymbol{T}_{\boldsymbol{s}}$ and ${ }_{c a l} \boldsymbol{T}_{\boldsymbol{s}}$.

Table 10. Comparison with Calculated and Experimental Strengths of Subassemblage Specimen

\begin{tabular}{|c|c|c|c|c|c|c|c|c|c|}
\hline \multirow{2}{*}{\multicolumn{2}{|c|}{ specimen }} & ${ }_{c a l} T_{y}$ & $\exp _{y}$ & \multirow{2}{*}{${ }_{\exp } T_{y} /{ }_{c a l} T_{y}$} & ${ }_{c a l} T_{u}$ & $\exp _{u}$ & \multirow{3}{*}{$\frac{\exp _{u} T_{c a l} \boldsymbol{T}_{u}}{1.06}$} & \multicolumn{2}{|c|}{ failure mode } \\
\hline & & \multicolumn{2}{|c|}{$(\mathrm{kN})$} & & \multicolumn{2}{|c|}{$(\mathrm{kN})$} & & predicted & exp. \\
\hline \multirow{3}{*}{ A } & 1 & \multirow{3}{*}{117} & 132 & 1.13 & \multirow{3}{*}{173} & 184 & & \multirow{3}{*}{ mode 6} & \multirow{3}{*}{ mode 6} \\
\hline & 2 & & 133 & 1.14 & & 196 & 1.13 & & \\
\hline & 3 & & 117 & 1.00 & & 178 & 1.03 & & \\
\hline \multirow{3}{*}{ B } & 1 & \multirow{3}{*}{$\begin{array}{c}82 \\
(93)\end{array}$} & 93 & 1.14 & \multirow{3}{*}{ (112) } & $146<$ & $(1.30)<$ & \multirow{3}{*}{$\begin{array}{c}\text { mode } 6 \\
\text { (mode } 10)\end{array}$} & \multirow{3}{*}{ - } \\
\hline & 2 & & 102 & 1.25 & & $165<$ & $(1.47)<$ & & \\
\hline & 3 & & 102 & 1.25 & & $167<$ & $(1.49)<$ & & \\
\hline \multirow{3}{*}{$\mathrm{C}$} & 1 & \multirow{3}{*}{397} & 417 & 1.05 & \multirow{3}{*}{ (464) } & $585<$ & $(1.26)<$ & \multirow{3}{*}{ mode 9} & \multirow{3}{*}{-} \\
\hline & 2 & & 417 & 1.05 & & $578<$ & $(1.25)<$ & & \\
\hline & 3 & & 417 & 1.05 & & $562<$ & $(1.21)<$ & & \\
\hline \multirow{3}{*}{$\mathrm{D}$} & 1 & \multirow{3}{*}{203} & 272 & 1.34 & \multirow{3}{*}{315} & 377 & 1.20 & \multirow{3}{*}{ mode 4} & \multirow{3}{*}{ mode 4} \\
\hline & 2 & & 272 & 1.34 & & 330 & 1.05 & & \\
\hline & 3 & & 278 & 1.37 & & 374 & 1.19 & & \\
\hline
\end{tabular}

In the case of B-type specimen, the calculated yield strengths for modes 6 and 9 are not so far apart from each other. For this reason, it is conjectured that after the specimen yields initially at mode 6 , the deflection of the column becomes significantly so as to form mode 10. After forming such yield mechanism, the specimen resists against external tensile force, but deforms excessively from the original shape, because of sufficient axial resistant capacity of column webs parallel to the longitudinal direction of the specimen. In the case of C-type specimen, since the tee bracket web yields at $468 \mathrm{kN}$, the specimen deforms both at the column and the web. From the table, the design formulae may be applicable for prediction of strength of subassemblage specimen. 


\section{CONCLUSIONS}

Performance on split tee bracket-to-RHS column connection using both plug weld and fillet weld has been investigated by conducting two series of tests. The following conclusions can be deduced from the test results:

[1] Strength of plug weld alone has been initially examined by using simple T-T specimen, and it has been shown that the yielding can be predicted fairly well by proposed design equation, although the ultimate strength by design equation evaluates considerably lower than the experimental result.

[2] Strength of the subassemblage composed of split tee, RHS column and plug welded portion as well as fillet welded portion has been evaluated by comparing the design strength with the experimental result. The result of comparison has shown that the proposed design formulae give fairly well prediction of yield strength. This conclusion can be applied to the subassemblages composed of the columns of width-thickness ratio of about 20.

[3] Fillet welding arranged at the corners of tee flange, is effective so that the connection, which consists of split tee bracket and RHS column, can behave integrated until the ultimate state.

[4] The plug weld alone appears to give greater ductility.

\section{NOTATIONS}

\section{Lower cases}

a throat thickness of corner fillet weld

$\boldsymbol{d}_{\boldsymbol{p}} \quad$ diameter of plug weld

I effective length of each projection of tee bracket flange

$\boldsymbol{l}_{1} \quad$ distance between the center of plug weld and the end of flange

$\boldsymbol{I}_{2} \quad$ distance between the center of plug weld and the center of fillet weld

$\boldsymbol{I}_{w} \quad$ effective length of corner fillet weld

$\boldsymbol{I}_{w 1} \quad$ effective length of corner fillet weld along transverse direction of tee bracket flange

$\boldsymbol{I}_{\boldsymbol{w} 2}$ effective length of corner fillet weld along longitudinal direction of tee bracket flange

$\boldsymbol{m} \quad$ numeral from 1 to 4 , corresponding to mode 7 to 10

$n$ number of plug weld at each projection of tee bracket flange

$\boldsymbol{p}_{\text {fws }} \quad$ specific strength of corner fillet weld per unit length

$\boldsymbol{r} \quad$ radius of fillet of wide flange section

$\boldsymbol{r}_{\boldsymbol{c}} \quad$ corner radius of RHS column

$\boldsymbol{s} \quad$ letter indicating yielding state $\boldsymbol{y}$ or ultimate state $\boldsymbol{u}$

size size of fillet weld

$\boldsymbol{t}_{\boldsymbol{c}} \quad$ thickness of SHS column

$\boldsymbol{t}_{f} \quad$ thickness of tee bracket flange or upper flange of T-T specimen

$\boldsymbol{t}_{\boldsymbol{w}} \quad$ thickness of tee bracket web

$w \quad$ width of tee bracket

\section{Upper cases}

$\boldsymbol{B}_{\boldsymbol{c}} \quad$ outside dimension of RHS column

$\boldsymbol{B}_{\boldsymbol{m}} \quad$ partial length of yield line parallel to transverse direction of subassemblage specimen 
$\boldsymbol{H}_{\boldsymbol{c}} \quad$ length of RHS column used for subassemblage specimen

$\boldsymbol{H}_{\boldsymbol{m}} \quad$ partial length of yield line parallel to longitudinal direction of subassemblage specimen

$\boldsymbol{M}_{\mathbf{0 s}} \quad$ fully plastic or ultimate moment per unit width of bracket flange

$\boldsymbol{M}_{\text {fws }} \quad$ fully plastic or ultimate moment of fillet weld per unit length

$\boldsymbol{P}_{\boldsymbol{p}} \quad$ tensile force of plug weld

$\boldsymbol{P}_{\boldsymbol{p} 1 \mathrm{~s}} \quad$ specific tensile force of plug weld

$\boldsymbol{P}_{p 2 s} \quad$ specific tensile force caused by shear yielding or failure of plug weld

$\boldsymbol{P}_{p 3 s} \quad$ specific tensile force due to punching of RHS column plate

$\boldsymbol{P}_{\boldsymbol{p y}(\boldsymbol{e x})}$ experimental yield tensile force of plug weld

$\boldsymbol{P}_{p s(c a l)}$ estimated specific tensile force of plug weld

$\boldsymbol{P}_{p s(e x)} \quad$ specific tensile force of plug weld obtained from experiment

$\boldsymbol{P}_{\boldsymbol{p u}(\boldsymbol{e x})}$ experimental ultimate tensile force of plug weld

$\boldsymbol{P}_{\boldsymbol{r}} \quad$ prying force

$\boldsymbol{T} \quad$ applied tensile force

${ }_{c} \boldsymbol{T}_{\boldsymbol{s}} \quad$ specific tensile force transferred to the column through the tee bracket

${ }_{c} \boldsymbol{T}_{\boldsymbol{s m}} \quad$ specific tensile force transferred to the column through the tee bracket for mode 7 to 10

${ }_{\text {cal }} \boldsymbol{T}_{\boldsymbol{s}} \quad$ estimated specific tensile strength of subassemblage

$\boldsymbol{T}_{\boldsymbol{s}} \quad$ specific tensile strength of tee bracket

${ }_{\boldsymbol{t}} \boldsymbol{T}_{\boldsymbol{s 1}} \quad$ specific tensile strength of tee bracket stipulated by mode 4

${ }_{t} \boldsymbol{T}_{s 2} \quad$ specific tensile strength of tee bracket stipulated by mode 5

${ }_{t} \boldsymbol{T}_{\boldsymbol{s} 3} \quad$ specific tensile strength of tee bracket stipulated by mode 6

$\boldsymbol{T}_{\boldsymbol{y}} \quad$ applied tensile yield force

$\boldsymbol{X}_{\boldsymbol{m}} \quad$ projected length of yield line along longitudinal direction of subassemblage specimen

$\boldsymbol{Y}_{\boldsymbol{m}} \quad$ projected length of yield line along transverse direction of subassemblage specimen

\section{Greek letters}

$\delta_{c} \quad$ local distortion at the center of T-T specimen

$\delta_{p} \quad$ local distortion at plug weld

$\delta_{r} \quad$ local distortion at the end of upper flange of T-T specimen

$\theta_{\text {end }} \quad$ rotation angle evaluated from $\theta_{\text {end }}=\left(\delta_{c}-\delta_{p}\right) / l_{2}$

$\sigma_{c s} \quad$ specific tensile strength of RHS column plate

$\sigma_{f s} \quad$ specific tensile strength of tee bracket flange

$\sigma_{\text {fws }} \quad$ specific strength of corner fillet weld per unit area

$\sigma_{p s} \quad$ specific tensile strength of plug weld

\section{ACKNOWLEDGEMENT}

Authors acknowledge to earnest contribution of the persons concerned of Tohji Co. and Watahan Co. for their fabrication of specimens used in this study. 


\section{REFERENCES}

[1] The Architectural Institute of Japan, “Design Standard for Steel Structures”, The Architectural Institute of Japan, 1979.

[2] The Architectural Institute of Japan, "Design Standard for Steel Structures-Based on Allowable Stress Concept-”, The Architectural Institute of Japan, 2005, (in Japanese)

[3] American Welding Society, “AWS-D1.1 Structural Welding Code-Steel”, American Welding Society, 2000.

[4] American Institute of Steel Construction, "Specification for Structural Steel Buildings", American Institute of Steel Construction, Inc., 2005.

[5] Faella, C., Piluso, V. and Rizzano, G., "Structural Steel Semirigid Connections: Theory, Design and Software, Chapter 4”, CRC Press LLC, 1999.

[6] Faella, C., Piluso, V. and Rizzano, G., "Moment Resistant Connections of Steel Frames in Seismic Areas: 2.2 Plastic Deformation Capacity of Bolted T-stubs: Theoretical Analysis and Testing”, E \& FN Spon, 2000.

[7] Morita K., Yamamoto N. and Ebato K., "Analysis on the Strength of Unstiffened Beam Flange to RHS Column Connections based on the Combined Yield Line Model”, Tubular Structures, the Third International Symposium, Elsevier Applied Science, 1990, pp.164-171.

[8] Yamamoto N. , Morita K. and Watanabe H., "Effect of Stiffener on the Strength of Connection between Beam and RHS column”, Tubular Structures, the Third International Symposium, Elsevier Applied Science, 1990, pp.172-179.

[9] Harada Y., Nakagawa H. and Morita K., "Out-of-Plane Behavior of Column Skin Plate in RHS Column-to-Split-T Tensile Connection with High-Strength Bolts”, Journal of Structural and Construction Engineering (Transactions of A.I.J.), 2003, No.567, pp.173-180, (in Japanese). 